\title{
Aumento na sobrevivência após vitrificação de oócitos bovinos imaturos em recipientes com maior condutividade térmica e nitrogênio super-resfriado
}

\author{
Increased survival of bovine immature oocytes after vitrification in loading materials of high thermal \\ conductivity and super cooled liquid nitrogen
}

\author{
Silverio Bunn ${ }^{1}$, Fabiano Buss Cruz $^{1}$, Cesar Augusto Ferraz Pedrazzi ${ }^{2}$, Marcelo Bertolini ${ }^{1}$, Arnaldo Diniz \\ Vieira $^{1}$ \& Alceu Mezzalira ${ }^{1}$
}

\begin{abstract}
RESUMO
A condutividade térmica do recipiente pode alterar a velocidade de resfriamento e reaquecimento, durante a criopreservação de oócitos, influenciando sua viabilidade. Recipientes de diferentes condutividades térmicas foram comparados na vitrificação de oócitos bovinos. Oócitos imaturos $(\mathrm{n}=1454)$ foram expostos a uma solução de $20 \% \mathrm{EG}+20 \%$ DMSO e 0,5 M Sacarose, envasados em PM (palheta metálica inoxidável, n=265), MV (micropipeta de vidro, n=279), PB (palheta cortada em bisel, $\mathrm{n}=280$ ), OPS (open pulled straw, $\mathrm{n}=272$ ) e vitrificados em nitrogênio submetido ao vácuo. $\mathrm{O}$ reaquecimento foi realizado por 5 minutos de exposição a cada solução de sacarose $(0,30$ e $0,15 \mathrm{M})$, aquecidas a $35^{\circ} \mathrm{C}$. Como controle, 358 oócitos foram mantidos frescos, sem vitrificar. Os oócitos foram maturados e fecundados, sendo os prováveis zigotos cultivados em meio SOFaaci, a $39^{\circ} \mathrm{C}$, com $5 \% \mathrm{CO}_{2}, 5 \% \mathrm{O}_{2}$ e $90 \% \mathrm{~N}_{2}$, em umidade saturada. Não foram verificadas diferenças nas taxas de clivagem entre os tratamentos, que foram inferiores $(\mathrm{p}<0,05)$ ao grupo controle. Nos grupos vitrificados, maior taxa de blastocisto foi obtida com o tratamento PM $(10,2 \%)$, que foi superior $(\mathrm{p}<0,05)$ aos tratamentos OPS $(6,1 \%)$ e PB $(6,1 \%)$, não diferindo do grupo MV (8\%), embora com tendência de ser superior ( $\mathrm{p}<0,1)$. Os grupos tratados tiveram semelhantes taxas de eclosão que, todavia, foram inferiores ao controle. Conclui-se que o aumento da velocidade de resfriamento melhora a viabilidade após a vitrificação de oócitos bovinos imaturos, sendo que as palhetas metálicas, de maior condutividade, são mais efetivas do que as palhetas plásticas (OPS e PB), embora sem diferir da micropipeta de vidro (MV).
\end{abstract}

Descritores: vácuo, micropipeta de vidro, palheta de metal, OPS, oócitos, bovinos.

\section{ABSTRACT}

The thermal conductivity of the container can affect the cooling and warming rate during the oocyte cryopreservation, influencing its viability. Containers of different thermal conductivities were compared for the vitrification of bovine oocytes. Immature oocytes ( $\mathrm{n}=1454)$ were exposed to a $20 \% \mathrm{EG}+20 \%$ DMSO and $0.5 \mathrm{M}$ Sucrose solution, loaded into PM (stainless straws, $n=265$ ), MV (glass micropipettes, $n=279$ ), PB (beveled-cut straws, $n=280$ ), OPS (open pulled straws, $n=272$ ) and vitrified in nitrogen submitted to vacuum. Rewarming was performed by $5 \mathrm{~min}$ exposure to each sucrose solution ( 0.30 and $0.15 \mathrm{M}$ ), at $35^{\circ} \mathrm{C}$. As control, 358 oocytes were used fresh (non-vitrification). Oocytes were in vitro-matured and fertilized, with the presumptive zygotes being cultured in SOFaaci medium at $39^{\circ} \mathrm{C}$, with $5 \% \mathrm{CO}_{2}, 5 \% \mathrm{O}_{2}$ and $90 \% \mathrm{~N}_{2}$, in saturated humidity. No differences in cleavage rates were detected between treatments, being all lower than the control group $(\mathrm{p}<0.05)$. In the vitrified groups, the highest blastocyst rate was observed in the PM treatment $(10.2 \%)$, which in turn was higher $(\mathrm{p}<0.05)$ than both the OPS (6.1\%) and PB treatments (6.1\%). However, although a trend existed ( $\mathrm{p}<0.1)$, no difference was observed between the PB and the MV treatments (8\%). All treatment groups had identical hatching rates, which were lower than the control group. We concluded that the increase in cooling rates improved the viability of immature bovine oocytes after the vitrification, and that higher conductivity stainless straws were more effective for oocyte vitrification than plastic straws (OPS and PB), albeit not different from the glass micropipette (MV).

Key words: vacuum, glass micropipette, stainless straws, OPS, oocytes, bovine. 


\section{INTRODUÇÃO}

A criopreservação de oócitos possibilita o estabelecimento de bancos genéticos, mantendo a biodiversidade animal; flexibiliza a produção in vitro, proporcionando o avanço do melhoramento genético; e disponibiliza material para pesquisas básicas [6]. Entretanto, o alto teor lipídico, o baixo coeficiente de permeabilidade, a alta relação volume/superfície, o grande tamanho, as células do cumulus e o complexo citoesqueleto dos oócitos interferem negativamente na sua sobrevivência à criopreservação [9,10]. A metodologia mais adequada para criopreservar oócitos é a vitrificação [23], que, por sua alta velocidade de resfriamento, permite uma rápida passagem pela zona crítica de temperatura, na qual ocorrem as lesões às células [12]. As chamadas metodologias abertas, como as microdrops [6,7], electron microscope grids [15], open pulled straws (OPS) [22], micropipetas de vidro (MV) [16,18], o cryoloop [8] e o nylon mesh [1] proporcionam alta taxa de resfriamento. $\mathrm{O}$ emprego de vácuo, para eliminar o vapor de nitrogênio e seu efeito isolante, poderia ampliar ainda mais esta velocidade. $\mathrm{O}$ uso de nitrogênio sob vácuo, na vitrificação de oócitos envasados em OPS, aumentou as taxas de desenvolvimento embrionário [20]. As OPS têm baixa condutividade térmica, sendo possível que, materiais de maior condutividade, aumentem a velocidade de resfriamento e melhorem a viabilidade da técnica.

Este estudo teve como objetivo avaliar a influência de recipientes de diferentes condutividades térmicas (palhetas metálicas, micropipeta de vidro, OPS ou palhetas em bisel) sobre as taxas de embriões obtidas de oócitos bovinos imaturos, vitrificados em nitrogênio super-resfriado.

\section{MATERIAIS E MÉTODOS}

\section{Obtenção dos oócitos}

Ovários bovinos coletados em frigorífico foram transportados, em solução salina tamponada com fosfato (PBS), adicionada de $100 \mathrm{UI}$ penicilina/mL e $0,05 \mathrm{mg}$ estreptomicina/ $\mathrm{mL}$, com temperatura entre 30 e $35^{\circ} \mathrm{C}$. O tempo decorrido desde a obtenção dos ovários e o seu processamento ficou em torno de $5 \mathrm{~h}$. No laboratório, os ovários foram lavados em PBS, procedendo-se, a seguir, a punção dos folículos entre 2 a $8 \mathrm{~mm}$ de diâmetro, através do emprego de uma agulha $18 \mathrm{G}$, ligada a uma linha de vácuo, utilizandose pressão suficiente para aspirar $20 \mathrm{~mL} /$ minuto de água. Após a sedimentação do líquido folicular, procedia-se a busca dos complexos cumulus oócitos (CCO's) em estereomicroscópio sendo, tanto a busca como a seleção, realizadas em líquido folicular centrifugado, durante 5 minutos.

Foram utilizados 1454 oócitos com citoplasma homogêneo e totalmente envoltos por células compactas do cumulus, divididos aleatoriamente entre os grupos experimentais, sendo 265 no grupo palhetas metálicas (PM), 279 no grupo micropipetas de vidro (MV), 280 no grupo palhetas em bisel (PB), 272 no grupo palhetas abertas e estiradas (OPS) e 358 no grupo controle, não-vitrificado. $\mathrm{O}$ experimento teve 11 repetições, sendo o grupo controle mantido em líquido folicular centrifugado até o final da vitrificação, quando foi submetido à maturação, juntamente com os oócitos vitrificados.

\section{Soluções de vitrificação e reaquecimento}

As soluções empregadas na vitrificação eram preparadas imediatamente antes do uso, em placas de quatro poços (Nunc - Roskilde - Dinamarca). No poço 1 , adicionavam-se $400 \mu \mathrm{L}$ de TCM 199 adicionado de Hepes (TCM Hepes), com $20 \%$ de soro de égua em estro (SEE) $+50 \mu \mathrm{L}$ de EG e $+50 \mu \mathrm{L}$ de DMSO (Solução de equilíbrio). No poço 2, a solução era composta por $300 \mu \mathrm{L}$ de TCM Hepes, com $0,8 \mathrm{M}$ de sacarose, na qual adicionavam-se $100 \mu \mathrm{L}$ de EG + $100 \mu \mathrm{L}$ de DMSO (Solução de vitrificação). Nos poços 3 e 4 depositavam-se $400 \mu \mathrm{L}$ de TCM Hepes com $20 \%$ de SEE.

A solução de reaquecimento também era preparada em placa de quatro poços, depositando-se $400 \mu \mathrm{L}$ de solução de sacarose a $0,8 \mathrm{M}$ em TCM Hepes, adicionado de $20 \%$ de SEE $+800 \mu \mathrm{L}$ de TCM Hepes com $20 \%$ de SEE no poço 1, obtendo-se uma solução final de, aproximadamente, 0,3 M. No poço 2, depositavamse $200 \mu \mathrm{L}$ de solução de sacarose a $0,8 \mathrm{M}+400 \mu \mathrm{L}$ de TCM Hepes, obtendo a mesma solução do poço 1 . No poço 3, depositavam-se $100 \mu \mathrm{L}$ de solução de sacarose a $0,8 \mathrm{M}+400 \mu \mathrm{L}$ de TCM HEPES, obtendo-se uma solução final com aproximadamente $0,15 \mathrm{M}$ de sacarose. Finalmente, no poço 4 , depositavam-se $400 \mu \mathrm{L}$ de TCM Hepes.

Os oócitos eram expostos à solução de equilíbrio, durante 30 segundos, e, após esse período, colocados na solução de vitrificação que se encontrava no 
interior da placa, em uma gota de, aproximadamente, $100 \mu \mathrm{L}$ e, em seguida, em uma microgota de $2-5 \mu \mathrm{L}$, quando eram envasados. $\mathrm{O}$ tempo de permanência na solução de vitrificação era de 20 segundos.

\section{Envase}

Os oócitos eram envasados em grupos de 5 ou 6 , sendo que em cada repetição eram vitrificados 30 oócitos por tratamento. Foram utilizadas embalagens constituídas por diferentes materiais, dependendo do tratamento. As palhetas metálicas (PM) utilizadas no tratamento PM foram feitas a partir da parte metálica de cateteres (BD Insyte-W) medindo 1.1 x $48 \mathrm{~mm}$, dos quais extraiu-se o êmbolo e a porção em bisel. No tratamento de micropipetas de vidro (MV), as micropipetas foram confeccionadas a partir de capilares de micro-hematócrito, estirados manualmente, após o aquecimento em chama. No tratamento palheta em bisel (PB), foram utilizadas palhetas de $0,25 \mathrm{~mL}$, das quais foram retirados os êmbolos, sendo uma das extremidades cortadas na diagonal, de forma a produzirem uma extremidade em bisel. Para o tratamento open pulled straw (OPS) foram utilizadas palhetas de $0,25 \mathrm{~mL}$, aquecidas em placa aquecedora (Fanem - modelo 250) e estiradas manualmente, até obter um diâmetro aproximado de um terço do original.

\section{Vitrificação}

Para a vitrificação, utilizou-se o equipamento Nitrocooler, que era abastecido com aproximadamente $350 \mathrm{~mL}$ de nitrogênio líquido e mantido em funcionamento, para produção de vácuo, por um período aproximado de 5 minutos, quando ocorria a solidificação do nitrogênio. $\mathrm{O}$ equipamento era desligado, a tampa do nitrogênio aberta e os oócitos devidamente envasados eram, então, mergulhados no nitrogênio, em posição oblíqua. A seguir, os oócitos retirados do equipamento e depositados num recipiente contendo nitrogênio em atmosfera normal, em que eram mantidos até o momento do reaquecimento.

\section{Reaquecimento e remoção dos crioprotetores}

O reaquecimento era realizado através da exposição ao ar por 4 segundos, seguido da imersão da extremidade contendo os oócitos em 1,2 mL de uma solução de sacarose a 0,3 M, contido no poço 1 da placa de reaquecimento. Logo após serem localizados, os oócitos eram transferidos para o poço 2, contendo a mesma solução, porém sem a contaminação dos crioprotetores. Nesta solução, os oócitos permaneciam por 5 minutos, sendo, logo a seguir, transferidos para uma solução contendo $0,15 \mathrm{M}$ de sacarose (poço 3), em que permaneciam por mais 5 minutos. Ao final desse período, eram depositados em TCM Hepes e, então, submetidos à maturação.

\section{Maturação}

Após o reaquecimento, os oócitos vitrificados, bem como os do grupo controle, eram depositados em placas de quatro poços contendo $400 \mu \mathrm{l}$ de meio de maturação, composto por TCM-199 com sais de Earle (GIBCO BRL, Paisley, UK) adicionado de 26,2 mM de $\mathrm{NaHCO}_{3}, 25 \mathrm{mM}$ de Hepes, 0,2 $\mathrm{mM}$ de piruvato de sódio, 0,01 UI de FSH/mL, 0,5 $\mu \mathrm{g} / \mathrm{mL}$ de LH e $10 \%$ de $\mathrm{SEE}$, por $24 \mathrm{~h}$ à $39^{\circ} \mathrm{C}$, em incubadora com atmosfera de $5 \%$ de $\mathrm{CO}_{2}$ e $95 \%$ de umidade relativa.

\section{Fecundação}

A fecundação foi realizada com $2 \times 10^{6}$ espermatozóides/mL, selecionados pelo método swim up, em meio Talp-Fert, adicionado de $30 \mu \mathrm{g} / \mathrm{mL}$ de heparina, $0,72 \mu \mathrm{g} / \mathrm{mL}$ de penicilamina, $0,26 \mu \mathrm{g} / \mathrm{mL}$ de hipotaurina e $0,04 \mu \mathrm{g} / \mathrm{mL}$ de epinefrina, com incu-bação de 18 a 20h, em incubadora de cultivo com $5 \% \mathrm{CO}_{2} \mathrm{e}$ $95 \%$ de umidade relativa.

\section{Produção dos embriões}

Ao final do período de fecundação, era procedida a remoção das células do cumulus através de agitação mecânica e a transferência das estruturas para o meio SOFaaci, suplementado com 5\% de SEE e mantido sob óleo mineral em incubadora de cultivo a $5 \% \mathrm{CO}_{2}$ e $95 \%$ de umidade relativa. Após $24 \mathrm{~h}$ de cultivo, as estruturas não-clivadas eram removidas, utilizando-se a partir daí o cultivo em bolsas impermeáveis (BAGS) [21], com atmosfera de 5\% de $\mathrm{CO}_{2}, 5 \%$ de $\mathrm{O}_{2}, 90 \%$ de $\mathrm{N}_{2}$, por $130 \mathrm{~h}$ adicionais, quando era verificada a taxa de desenvolvimento embrionário. Os critérios de viabilidade adotados foram as taxas médias percentuais de clivagem, de blastocistos, e de eclosão. Os dados foram submetidos à análise de variância, utilizando-se o pacote estatístico do SAS (SAS Institute, 1998), sendo previamente testados para a normalidade dos resíduos pelo teste de Shapiro-Wilk [19]. As médias foram comparadas pelo teste de Tukey, com nível de significância de $5 \%$. 


\section{RESULTADOS}

Com aproximadamente cinco minutos de funcionamento do equipamento Nitrocooler, foi observada a solidificação do nitrogênio líquido, inicialmente com a formação de uma floculação.

Dos 1454 oócitos utilizados no experimento, 1096 foram vitrificados, dos quais se obteve uma taxa média de $34,9 \%$ de clivagem e 7,6\% atingiram o estádio de blastocisto. Não foram observadas diferenças significativas entre as taxas de clivagem nos diferentes grupos experimentais que, todavia, foram significativamente inferiores $(\mathrm{P}<0,05)$ ao grupo controle $(86 \%)$, como demonstrado na Tabela 1.

Em relação à taxa de blastocistos, o grupo PM apresentou taxa significativamente superior $(10,2 \%)$ aos tratamentos OPS $(6,1 \%)$ e PB $(6,1 \%)$, respectivamente $(\mathrm{P}<0,05)$. Os grupos PM $(10,2 \%)$ e MV $(8 \%)$ não diferiam entre si, sendo observada, entretanto, uma tendência de superioridade $(\mathrm{P}<0,1)$ do grupo $\mathrm{PM}$. A taxa de blastocistos do grupo controle (35\%) foi superior $(\mathrm{P}<0,05)$ aos grupos vitri-ficados (Tabela 1). $\mathrm{O}$ percentual de eclosão nos grupos vitrificados apresentou uma variação entre 41 e $56 \%$, não sendo constatada diferença significativa. Entretanto, todos os grupos vitrificados apresentaram taxas de eclosão significativamente inferiores ao grupo controle não-vitrificado (77\%; $\mathrm{P}<0,05)$.

\section{DISCUSSÃO}

O primeiro relato de animal nascido (camundongo) a partir de um oócito criopreservado ocorreu em 1976. Desde então, embora tenha se obtido progresso, continua a necessidade da adequação da criopreservação de oócitos nas diferentes espécies, incluindo a humana. Neste mesmo período, milhares de animais de mais de 20 espécies, além de milhares de crianças, nasceram a partir de embriões criopreservados [11]. Para otimizar a criopreservação de oócitos, uma variedade de condições e métodos vêm sendo utilizadas, algumas com rigorosas formulações matemáticas, buscando prever o comportamento de embriões e oócitos em temperaturas subzero e, em outras, comparando diferentes compostos, suplementos, equipamentos e velocidades de resfriamento e de reaquecimento $[9,11]$.

Em função das características dos oócitos, principalmente o alto teor lipídico, metodologias com maior taxa de resfriamento e de reaquecimento são mais indicadas, destacando-se a vitrificação [23], especialmente com as chamadas metodologias abertas, que, pela alta velocidade de resfriamento, permite passar rapidamente pela faixa crítica de temperatura, na qual as lesões são produzidas [12], principalmente pela mudança de fase dos lipídios.

Tabela 1. Desenvolvimento embrionário de oócitos imaturos vitrificados em nitrogênio líquido submetido ao vácuo e envasados em diferentes recipientes.

\begin{tabular}{lcccc}
\hline $\begin{array}{c}\text { Tratamentos/ } \\
\text { Vitrificação em: }\end{array}$ & $\begin{array}{c}\text { Oócitos maturados } \\
(\mathbf{n})\end{array}$ & $\begin{array}{c}\text { Clivagem } \\
(\%)\end{array}$ & $\begin{array}{c}\text { Blastocistos } \\
(\%)\end{array}$ & $\begin{array}{c}\text { Eclosão* } \\
(\%)\end{array}$ \\
\hline Palhetas estiradas - OPS & 272 & $31,4^{\mathrm{a}}$ & $6,1^{\mathrm{a}}$ & $50,0^{\mathrm{a}}$ \\
Palhetas em bisel - PB & 280 & $32,6^{\mathrm{a}}$ & $6,1^{\mathrm{a}}$ & $41,0^{\mathrm{a}}$ \\
Palhetas metálicas - PM & 265 & $43,7^{\mathrm{a}}$ & $10,2^{\mathrm{b}}$ & $53,0^{\mathrm{a}}$ \\
Micropipetas vidro - MV & 279 & $31,8^{\mathrm{a}}$ & $8,0^{\mathrm{ab}}$ & $56,0^{\mathrm{a}}$ \\
Controle não-vitrificado & 358 & $86,0^{\mathrm{b}}$ & $35,0^{\mathrm{c}}$ & $77,0^{\mathrm{b}}$ \\
\multicolumn{1}{c}{ Total/Média } & 1454 & 45,1 & 13,1 & 55,4 \\
\hline
\end{tabular}

\footnotetext{
a,b,c Diferentes letras na mesma coluna indicam diferença estatística $(\mathrm{P}<0,05)$.

*Calculada sobre a taxa de blastocistos.
} 
Além das metodologias abertas de vitrificação, a taxa de resfriamento pode aumentar pela aplicação de vácuo ao nitrogênio líquido. O equipamento Nitrocooler, utilizado neste experimento, proporcionou a condição de vácuo, determinando a solidifi-cação do nitrogênio líquido e a queda de sua temperatura para $210^{\circ} \mathrm{C}$ (ponto de fusão), além da mudança do seu comportamento estático. Imediatamente após a abertura do recipiente hermético, contendo o nitrogênio solidificado, este se liquefez, porém mantendo, por cerca de cinco minutos, a característica de não ebulição, quando são mergulhados os recipientes contendo os oócitos, proporcionando assim maior difusão térmica. Trabalhos anteriores de nosso laboratório [20] demonstraram que o uso do nitrogênio super-resfriado aumenta a viabilidade embrionária após a criopreservação de oócitos. Esta melhora na taxa de embriões foi atribuída à maior velocidade de resfriamento com a conseqüente redução no tempo de exposição à faixa crítica de temperatura [2], que se centra entre 13 e $20^{\circ} \mathrm{C}$, prevenindo, dessa forma, os danos.

As taxas de clivagem observadas entre os grupos vitrificados foram semelhantes, sendo MV $(31,8 \%)$, PB $(32,64 \%)$, OPS $(31,43 \%)$ e PM $(43 \%)$. Estas taxas se assemelham às obtidas em trabalhos previamente desenvolvidos no laboratório, ou seja, 46 a $49 \%$ [24] e 33,9 a 41,2\% [20], sendo ainda comparáveis às obtidas por outros autores após a vitrificação de oócitos bovinos imaturos $(55,7 \%)$ [6] ou maturados $(49,1 \%$ [17] e 50\% [22]). A clivagem é um bom indicativo de sobrevivência após a criopreservação, e as taxas obtidas neste estudo e nos demais trabalhos atestam a viabilidade do processo. Todavia, embora a clivagem dos grupos vitrificados seja satisfatória, foi muito inferior à observada no grupo de controle (86\%), demonstrando que o processo de vitrificação utilizado, independente do tipo de recipiente empregado, ainda é danoso para os oócitos. Após a vitrificação de oócitos imaturos, estudos demonstraram alterações na configuração dos fusos meióticos [6], que foram dependentes do tempo de exposição aos crioprotetores antes e durante a vitrificação. Estas alterações, além de outros possíveis danos subcelulares, podem explicar a razão da redução nas taxas de clivagem e do reduzido número de estruturas clivadas que atingem estágios mais avançados como blastocisto.

Também no grupo controle houve uma acentuada diferença entre a taxa de clivagem $(86 \%)$ e a taxa de blastocistos (35\%), demonstrando que fatores ainda não identificados e, provavelmente relacionados ao processo de cultivo embrionário [13,14], não oferecem as melhores condições para o desenvolvimento do embrião. É provável que, com oócitos vitrificados, esse fenômeno seja intensificado e, assim, determine a maior redução na taxa de blastocistos. Em função disso, embora a taxa de clivagem seja um bom critério para avaliar a sobrevivência, não é um parâmetro satisfatório para avaliar a posterior viabilidade de desenvolvimento de oócitos [3].

A literatura é escassa em trabalhos comparando diferentes recipientes de envase na vitrificação de oócitos. A vitrificação de oócitos bovinos maturados, com o emprego de OPS ou de micropipetas de vidro (MV), foi avaliado, não havendo diferença na taxa de blastocistos dos dois grupos, $10 \%$ para MV e $8 \%$ para OPS [18].

Neste estudo, os materiais empregados para a confecção dos contêineres usados no envase dos oócitos, para a vitrificação, possui marcante diferença. O aço inoxidável possui condutividade térmica muito superior ao plástico [4], podendo chegar a oitenta vezes, sendo ainda vinte vezes superior à condutividade do vidro [5]. Isto explica as melhores taxas de desenvolvimento embrionário obtidas com as palhetas metálicas neste estudo. A taxa de blastocistos do tratamento PM $(10,2 \%)$ foi superior $(\mathrm{p}<0,05)$ aos grupos OPS e PB $(6,1 \%$ e $6,1 \%)$, respectivamente. Observou-se uma tendência de superioridade ( $<<0,1)$ do grupo PM em relação ao grupo MV (8\%), que tem a segunda maior condutividade entre os materiais testados. Entretanto, o tratamento MV não diferiu estatisticamente dos tratamentos OPS e PB.

Está bem documentado que, no processo de vitrificação, o aumento na velocidade de resfriamento e reaquecimento aumenta a viabilidade e a taxa de embriões $[2,15,20]$. Também neste estudo, as maiores taxas de desenvolvimento embrionário foram obtidas com a utilização da palheta de metal, recipiente que apresenta maior condutividade térmica, confirmando o efeito positivo do aumento da velocidade de resfriamento na vitrificação de oócitos bovinos.

No tratamento PB, era esperado uma viabilidade semelhante às embalagens de maior condutividade térmica, já que a maior parte da gota contendo os embriões é exposta diretamente ao nitrogênio. A menor viabilidade observada pode ter sido devido ao efeito isolante da parede da palheta, que é bastante espessa. 
A qualidade intrínseca do oócito é o fator chave para determinar a taxa de blastocistos, enquanto o período de cultivo após a fecundação é o mais crítico na determinação da qualidade embrionária $[13,14]$. É possível que o processo de vitrificação utilizado neste estudo tenha afetado negativamente a qualidade dos oócitos. Da mesma maneira, as circunstâncias de cultivo empregadas a partir da fecundação não devem ter proporcionado condições para a total recuperação dos oócitos vitrificados, o que explica a diferença entre as taxas de eclosão dos tratamentos vitrificados em relação ao grupo controle.

\section{CONCLUSÕES}

Os resultados obtidos neste estudo permitem concluir que (a) recipientes de maior condutividade térmica, empregados no envase de oócitos bovinos imaturos, melhoram a sua viabilidade durante o processo de vitrificação e (b) a utilização de palhetas metálicas confeccionadas a partir de cateteres é de baixo custo, fácil armazenamento em botijões criogênicos, e proporcionam maior taxa de embriões após a vitrificação de oócitos bovinos imaturos.

Agradecimentos. Ao CNPq, pelo suporte financeiro. À UDESC, pelo fornecimento de bolsa de estudo. Ao Frigorífico Verdi, pelo fornecimento dos ovários bovinos.

\section{REFERÊNCIAS}

1 Abe Y., Hara K., Matsumoto H., Kobayashi J., Sasada H., Ekwall H., Rodriguez-Martinez H. \& Sato E. 2005. Feasibility of a Nylon-Mesh Holder for Vitrification of Bovine Germinal Vesicle Oocytes in Subsequent Production of Viable Blastocysts. Biology of Reproduction. 72: 1416-1420.

2 Arav A., Zeron Y., Leslie S.B., Behboodi E., Anderson G.B. \& Crowe J.H. 1996. Phase transition temperature and chilling sensitivity of bovine oocytes. Cryobiology. 33: 589-599.

3 Fuku E.J., Liu J. \& Downey B.R. 1995. In vitro viability and ultrastructural changes in bovine oocytes treated with a vitrification solution. Molecular Reproduction and Development. 40: 177-185.

4 Halliday D., Resnick R. \& Walker J., 1996. Fundamentos de Física. Gravitação, ondas e termodinâmica. 4 ed., Rio de Janeiro: Editora Afiliada.

5 He X., Park E.Y., Fowler A., Yarmush M.L. \& Toner M. 2008. Vitrification by ultra-fast cooling at a low concentration of cryoprotectants in a quartz micro-capillary: a study using murine embryonic stem cells. Cryobiology. 56: $223-232$.

6 Kim D.H., Park H.S., Kim S.W., Hwang I.S., Yang B.C., Im G.S., Chung H.J., Seong H.W., Moon S.J. \& Yang B.S. 2007. Vitrification of immature bovine oocytes by the microdrop method. Journal of Reproduction and Development. 53: 843851.

7 Landa V. \& Tepla O. 1990. Cryopreservation of mouse 8-cell embryos in microdrops. Folia Biologica (Praha). 36: 153158.

8 Lane M., Schoolcraft W.B. \& Gardner D.K. 1999. Vitrification of mouse and human blastocysts using a novel cryoloop container-less technique. Fertility and Sterility. 72: 1073-1078.

9 Ledda S., Bogliolo L., Succu S., Ariu F., Bebbere D., Leoni G.G. \& Naitana S. 2006. Oocyte cryopreservation: oocyte assessment and strategies for improving survival. Reproduction, Fertility and Development. 19: 13-23.

10 Ledda S., Leoni G., Bogliolo L. \& Naitana S. 2001. Oocyte cryopreservation and ovarian tissue banking. Theriogenology. 55: $1359-1371$.

11 Leibo S.P. 2008. Cryopreservation of oocytes and embryos: optimization by theoretical versus empirical analysis. Theriogenology. 69: 37-47.

12 Liebermann J., Nawroth F., Isachenko V., Isachenko E., Rahimi G. \& Tucker M.J. 2002. Potential importance of vitrification in reproductive medicine. Biology of Reproduction. 67: 1671-1680.

13 Lonergan P., Rizos D., Gutierrez-Adan A., Fair T. \& Boland M.P. 2003. Oocyte and embryo quality: effect of origin, culture conditions and gene expression patterns. Reproduction in Domestic Animals. 38: 259-267.

14 Lonergan P., Rizos D., Kanka J., Nemcova L., Mbaye A.M., Kingston M., Wade M., Duffy P. \& Boland M.P. 2003. Temporal sensitivity of bovine embryos to culture environment after fertilization and the implications for blastocyst quality. Reproduction. 126: 337-346.

15 Martino A., Songsasen N. \& Leibo S.P. 1996. Development into blastocysts of bovine oocytes cryopreserved by ultrarapid cooling. Biology of Reproduction. 54: 1059-1069. 
16 Mezzalira A., Barbieri D.P., Muller F., Pinho C.C., Silva C.A.M., Rubin M.I. \& Bernardi M.L. 1999. Vitrificação de ovócitos bovinos em micropipetas de vidro. Arquivos da Faculdade de Veterinária da UFRGS. 27: 262.

17 Mezzalira A., Vieira A.D., Barbieri D.P., Machado M.F., Thaler Neto A., Bernardi M.L., Silva C.A.M. \& Rubin M.I. 2002. Vitrificação de oócitos e embriões bovinos produzidos in vitro e expostos à citocalasina B. Brazilian Journal of Veterinary Research and Animal Science. 39: 260-265.

18 Mezzalira A., Vieira A.D., Cruz F.B., Barbieri D.P. \& Damiani J.C. 2002. Vitrificação de ovócitos bovinos com a utilização de micropipetas de vidro ou palhetas estiradas. Revista de Ciências Agroveterinárias. 2: 108-114.

19 Santana D.G. \& Ranal M.A. 2004. Análise estatística. In: Ferreira A. G.\& Borghetti F. Germinação - do básico ao aplicado (Ed). Porto Alegre: ArtMed, pp. 197-208.

20 Santos R.M.D., Barreta M.H., Frajblat M., Cucco D.C., Mezzalira J.C., Bunn S., Cruz F.B., Vieira A.D. \& Mezzalira A. 2006. Vacuum-cooled liquid nitrogen increases the developmental ability of vitrified-warmed bovine oocytes. Ciência Rural. 36: 1501-1506.

21 Vajta G., Holm P., Greve T. \& Callesen H. 1997. The submarine incubation system, a new tool for in vitro embryo culture: A technique report. Theriogenology. 48: 1379-1385.

22 Vajta G., Holm P., Kuwayama M., Booth P.J., Jacobsen H., Greve T. \& Callesen H. 1998. Open Pulled Straw (OPS) vitrification: a new way to reduce cryoinjuries of bovine ova and embryos. Molecular Reproduction and Development. 51: 53-58.

23 Vajta G. \& Kuwayama M. 2006. Improving cryopreservation systems. Theriogenology. 65: 236-244.

24 Vieira A.D., Mezzalira A., Barbieri D.P., Lehmkuhl R.C., Rubin M.I. \& Vajta G. 2002. Calves born after open pulled straw vitrification of immature bovine oocytes. Cryobiology. 45: 91-94. 